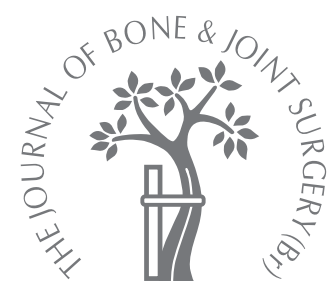

W. Pichler, W. Grechenig, N. P. Tesch, A. M. Weinberg, N. Heidari, H. Clement

From the Medical University of Graz, Graz, Austria

\title{
The risk of iatrogenic injury to the deep peroneal nerve in minimally invasive osteosynthesis of the tibia with the less invasive stabilisation system
}

A CADAVER STUDY

Percutaneous stabilisation of tibial fractures by locking plates has become an accepted form of osteosynthesis. A potential disadvantage of this technique is the risk of damage to the neurovascular bundles in the anterior and peroneal compartments. Our aim in this anatomical study was to examine the relationship of the deep peroneal nerve to a percutaneously-inserted Less Invasive Stabilisation System tibial plate in the lower limbs of 18 cadavers. Screws were inserted through stab incisions. The neurovascular bundle was dissected to reveal its relationship to the plate and screws.

In all cases, the deep peroneal nerve was in direct contact with the plate between the 11th and the 13th holes. In ten specimens the nerve crossed superficial to the plate, in six it was interposed between the plate and the bone and in the remaining two specimens it coursed at the edge of the plate.

Percutaneous insertion of plates with more than ten holes is not recommended because of the risk of injury to the neurovascular structures. When longer plates are required we suggest distal exposure so that the neurovascular bundle may be displayed and protected.

Stabilisation of tibial fractures by locking plates has become an increasingly common technique. ${ }^{1-5}$ The indication for their use also extends to metaphyseal fractures with or without intra-articular involvement. Current systems such as the Less Invasive Stabilisation System (LISS; Synthes, Solothurn, Switzerland) or the locking compression plate metaphyseal plates (Synthes) allow percutaneous insertion using a minimally invasive technique. These plates act as internal fixators bridging the fracture. ${ }^{6}$ After closed reduction of the fracture under fluoroscopic control, the plate is inserted through a small skin incision distal to Gerdy's tubercle. Commonly the distal screws are inserted percutaneously through small stab incisions. This may lead to injury to nerves or vessels. There is little information in the current literature on the risk of nerve injury in the minimally invasive technique of plating for tibial fractures. ${ }^{7-9}$

Our aim in this anatomical study was to determine the course of the deep peroneal nerve in relation to percutaneously-inserted LISS plates.

\section{Material and Methods}

We examined a total of 18 cadaver lower limbs preserved in accordance with Thiel's method. ${ }^{10}$ This unique embalming procedure was developed over a period of 30 years in the
Department of Anatomy of the University of Graz. It preserves tissue colour and consistency as well as allowing an almost full range of movement of joints. ${ }^{10}$ Each limb was examined by plain radiography to exclude those with pathological changes. Legs with evidence of arthritis, trauma or previous surgery were excluded from the study. The length of the tibia was recorded as the distance between the centre of the medial joint line of the knee and the tip of the medial malleolus. ${ }^{11}$ A mathematical method using stature regression formulae correlated tibial length with body height. ${ }^{11}$

The 18 legs were harvested from nine cadavers (four male, five female) with a mean age of 68.5 years (55 to 83). Using these unfractured legs, percutaneous LISS insertion was performed according to the recommended technique. In a supine position, a longitudinal skin incision of $5 \mathrm{~cm}$ to $6 \mathrm{~cm}$ was made from Gerdy's tubercle running distally. Tibialis anterior was then mobilised and a 13-hole LISS plate was inserted submuscularly, just superficial to the tibial periosteum (Fig. 1). The plate was advanced to the correct position in relation to the tibia according to the manufacturers instructions, and then checked by fluoroscopy in two different planes. Two proximal screws were inserted to secure the plate. The six distal 


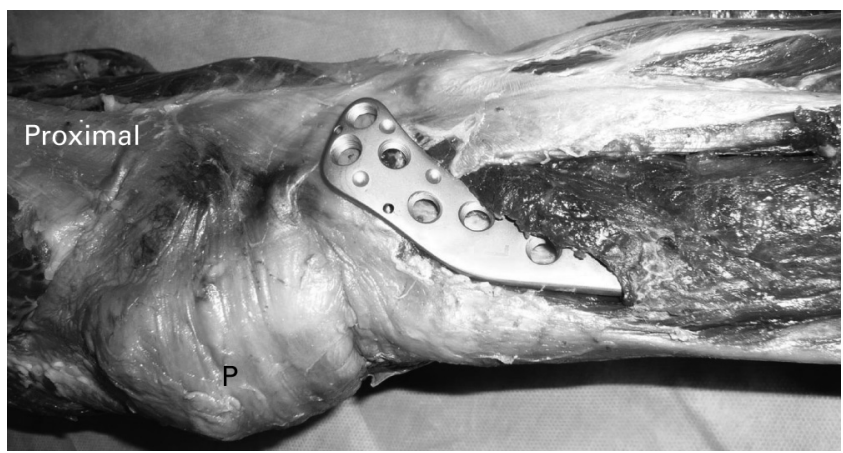

Fig. 1

Photograph showing the insertion of a LISS plate in a cadaver specimen $(\mathrm{P}=$ patella).

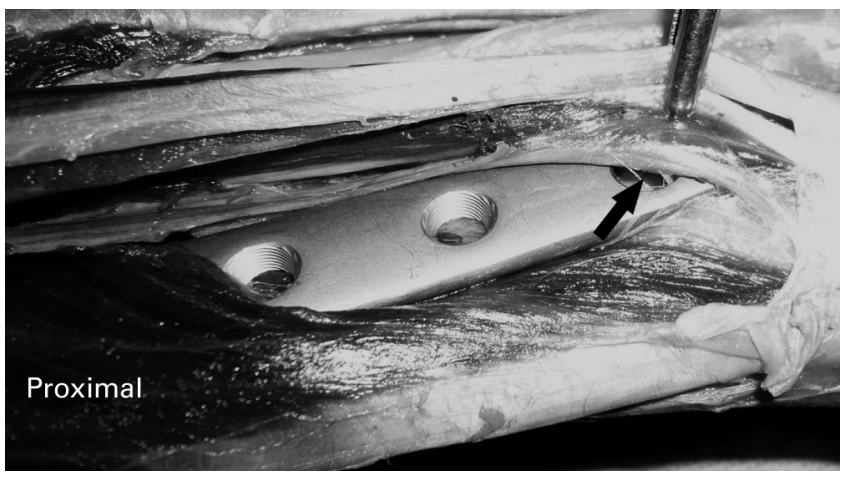

Fig. 2

Photograph showing the deep peroneal nerve crossing the plate in the area of a screw-hole (arrow).

locking screws of the 13-hole LISS plate (holes 8 to 13) were then inserted percutaneously according to the standard technique. The skin and the superficial fascia were removed and the deep peroneal nerve was exposed to demonstrate its relationship to the plate (Fig. 2). Photographic documentation was obtained in all cases. The results were entered into a computerised database.

Statistical analysis. All calculations were performed using Microsoft Excel 2003 software (Microsoft, Redmond, Washington). Chi-squared analysis with one degree of freedom was used to examine the relationship of gender and sides to the level at which the nerve crossed the plate. Student's $t$-test was used to study the relationship between the length of the tibia and the site where the nerve crossed the plate. A p-value $\leq 0.05$ was considered to be statistically significant.

\section{Results}

The mean tibial length was $36.9 \mathrm{~cm}$ (34.1 to 40.7). In all cases the nerve was in direct contact with the distal portion of the plate (Fig. 2). In nine cases the nerve crossed the plate at the level of the 13th hole, in three it crossed the plate at the level of the 11th hole and in a further three at the level of the 12th hole. In the remaining three cases the nerve skirted the distal edge of the plate.

In ten cases the nerve traversed the plate over its surface but in six it was trapped between the plate and the bone. In the other two cases, in skirting the distal edge of the plate the nerve did not actually cross the plate. No statistically significant association was found between gender (chisquared test, $\mathrm{p}=0.07$ ) or side (chi-squared test, $\mathrm{p}=0.09$ ), or the level at which the nerve crossed the plate. There was also no statistically significant relationship between the tibial length and the level at which the nerve crossed the plate (Student's $t$-test, $\mathrm{p}=0.07$ ).

\section{Discussion}

The development of biological internal fixation in recent years has been summarised by Perren. ${ }^{12}$ The emphasis of this approach has been to afford greater respect for the soft-tissue attachments to the bone. In many cases, closed reduction of tibial fractures is achieved under fluoroscopic control with the plate inserted through a small skin incision and the screws, especially those placed distally, inserted percutaneously. The course of the common peroneal nerve and its divisions has been described, ${ }^{13-16}$ with the route of the deep peroneal nerve accounting for its propensity to iatrogenic injury. It is, of course, important to note that injuries to the peroneal nerve from fracture fragments have also been reported. ${ }^{17}$ The risk of damage to the peroneal nerve is not restricted to its distal course. Jones et $\mathrm{al}^{9}$ showed that the proximal medial-to-lateral oblique locking screws in intramedullary tibial nails may come perilously close to the common peroneal nerve. Other procedures around the proximal tibia such as high tibial osteotomy, the insertion of proximal tibial external fixator pins and the placement of tibial traction pins have also been reported to have caused injury to the peroneal nerve. ${ }^{18,19}$ Zones of safety in relation to Gerdy's tubercle have been described in order to minimise the risk of iatrogenic injury to the peroneal nerve and its branches in the proximal tibia. ${ }^{20,21}$

Iatrogenic injury to the deep peroneal nerve in the distal portion of the leg may occur during any of the surgical manoeuvres necessary for the insertion of the distal screws including incision, blunt dissection down to the plate, drilling the screw hole and, finally, the insertion of the screw itself. There are few data in the current literature regarding nerve injuries associated with minimally invasive plate osteosynthesis of tibial fractures. Deangelis et $\mathrm{al}^{7}$ investigated the course of the superficial peroneal nerve and found it to be at significant risk during percutaneous screw placement at holes 11 to 13 of the 13-hold proximal tibial LISS plate. The authors advocated a larger incision and careful dissection down to the plate in this region to minimise this hazard. ${ }^{7}$ Wolinsky 
and Lee $^{8}$ precontoured plates distally to proximally along the anterolateral border of the tibia in ten cadavers in order to determine the anatomical structures at risk. They found the deep peroneal nerve and the anterior tibial vessels to be in particular danger with this technique.

Our findings suggest that the risk of iatrogenic injury to the deep peroneal nerve is greatest between the 11th and the 13th holes, when using a 13-hole LISS plate. At the level of the 11th hole the deep peroneal nerve and the artery and the accompanying vein of tibialis anterior are invariably in very close relation to the plate putting them in great danger of iatrogenic injury. The nerve crosses to the medial side of the artery in this region and maintains this relation down to the ankle. ${ }^{10,11,13}$ In six specimens, the nerve coursed beneath the plate, demonstrating a considerable risk of entrapment between the plate and the bone. In ten cases, the nerve crossed over the plate leaving it susceptible to injury from the skin incision, dissection down to the plate, drilling or insertion of the screw.

Tibialis anterior is on the lateral side of the tibia. Proximally, the neurovascular bundle courses lateral to the muscle and further distally is in direct contact with the tibial periosteum. Accordingly, we do not recommend percutaneous insertion of tibial LISS plates which have more than ten holes. If longer tibial LISS plates are needed, we advise the insertion of the plate under direct vision through an open distal approach to ensure its safe positioning on the tibia in relation to the neurovascular structures. In our study the tibiae used had no signs of injury of pathological changes, thus percutaneous insertion of the plate was performed easily. In the injured patient, application of the plate is made more challenging by the disrupted anatomy making percutaneous intervention more perilous.

In summary, percutaneous insertion of tibial LISS plates with more than ten holes is not recommended because of the high risk of iatrogenic injury to the deep peroneal nerve. By extending the distal approach, the nerve can be visualised and avoided.

No benefits in any form have been received or will be received from a commercial party related directly or indirectly to the subject of this article.

\section{References}

1. Cole PA, Zlowodzki M, Kregor PJ. Less Invasive Stabilization System (LISS) for fractures of the proximal tibia: indications, surgical technique and preliminary results of the UMC Clinical Trial. Injury 2003;34(Suppl 1):16-29.

2. Cole PA, Zlowodzki M, Kregor PJ. Treatment of proximal tibia fractures using the less invasive stabilization system: surgical experience and early clinical results in 77 fractures. J Orthop Trauma 2004;18:528-35.

3. Ricci WM, Rudzki JR, Borrelli J Jr. Treatment of complex proximal tibia fractures with the less invasive skeletal stabilization system. J Orthop Trauma 2004;18:521-7.

4. Stannard JP, Wilson TC, Volgas DA. The less invasive stabilization system in the treatment of complex fractures of the tibial plateau: short-term results. J Orthop Trauma 2004;18:552-8.

5. Phistkul Ph, McKinley T, Nepola JV, Marsh JL. Complications of locking plate fixation in complex proximal tibia injuries. J Orthop Trauma 2007;21:83-91.

6. Tong OG, Bavonratanavech S. AO manual of fracture management: minimally invasive plate osteosynthesis (MIPO). Georg Thieme, Stuttgart, New York, 2007.

7. Deangelis JP, Deangelis NA, Anderson R. Anatomy of the superficial peroneal nerve in relation to fixation of tibia fractures with the less invasive stabilization system. J Orthop Trauma 2004;18:536-9.

8. Wolinsky P, Lee $\mathbf{M}$. The distal approach for anterolateral plate fixation of the tibia: an anatomic study. J Orthop Trauma 2008;22:404-7.

9. Jones BG, Mehin R, Young D. Anatomical study of the placement of proximal oblique locking screws in intramedullary tibial nailing. J Bone Joint Surg [Br] 2007;89B:1495-7.

10. Thiel W. The preservation of the whole corpse with natural colour. Ann Anat 1992;174:185-95.

11. Knussmann R. Anthropologie: Handbuch der vergliechended biologie des menschen. Lehrbuch der anthropologie. d 1, Teil 1, 4. Auflage Stuttgart: Gustav Fischer Verlag, 1988.

12. Perren SM. Evolution of the internal fixation of long bone fractures: the scientific basis of biological fixation: choosing a new balance between stability and biology. $J$ Bone Joint Surg [Br] 2002;84-B:1093-110.

13. Hollinshead WH. Anatomy for Surgeons. Vol: 3 The back and limbs. New York: Harper \& Row, 1964.

14. Standring S, Ellis H, Berkovitz BKB. Gray's anatomy: the anatomical basis of clinical practice. Thirty ninth edition. New York: Elsevier Churchill Livingstone, 2005.

15. Leonhardt H, Tillmann B, Töndury G, Zilles K. In: Rauber A, Kopsch F, eds. Anatomie des Menschen. Leonhardt H, Band 1: Bewegungsapparat. Stuttgart: Georg Thieme, 1987

16. Adkison DP, Bosse MJ, Gaccione DR, Gabriel KR. Anatomical variations in the course of the superficial peroneal nerve. J Bone Joint Surg [Am]1991;73-A:112-14.

17. Pichler W, Clement H, Boldin C, Grechenig W, Tesch NP. Primary transection of the superficial peroneal nerve resulting from a distal fibula fracture. J Orthop Trauma 2007;21:212-14

18. Kirgis A, Albrecht S. Palsy of the deep peroneal nerve after proximal tibial osteotomy: an anatomical study. J Bone Joint Surg [Am]1992;74-A:1180-5.

19. Elgafy H, Ebraheim NA, Shaheen PE, Yeasting RA. Extensor hallucis longus innervation: an anatomic study. Clin Orthop 2002;398:245-51.

20. Stitgen SH, Cairns ER, Ebraheim NA, Niemann JM, Jackson WT. Anatomic considerations of pin placement in the proximal tibia and its relationship to the peroneal nerve. Clin Orthop 1992;278:134-7.

21. Rubel IF, Schwarzbard I, Leonard A, Cece D. Anatomic location of the peroneal nerve at the level of the proximal aspect of the tibia: Gerdy's safe zone. J Bone Joint Surg [Am]2004;86-A:1625-8. 